\title{
Pricing and lot sizing optimization in a two-echelon supply chain with a constrained Logit demand function
}

\author{
Yeison Díaz-Mateus ${ }^{a}$, Bibiana Forero $^{a}$, Héctor López-Ospina ${ }^{b^{*}}$ and Gabriel Zambrano-Rey ${ }^{a}$
}

${ }^{a}$ Industrial Engineering Department, Pontificia Universidad Javeriana, Cra 7 \#40-62, Ed. Jose Gabriel Maldonado P.3, Bogotá, Colombia ${ }^{b}$ Department of Industrial Engineering, Universidad del Norte, Km. 5 Via Puerto Colombia, Barranquilla, Colombia

\begin{tabular}{l}
\hline C H R O N I C L E \\
\hline Article history: \\
Received February 132017 \\
Received in Revised Format \\
April 12017 \\
Accepted June 162017 \\
Available online \\
June 162017 \\
\hline Keywords: \\
Constrained multinomial logit \\
Pricing \\
Lotsizing \\
Supply chain optimization \\
PSO
\end{tabular}

\section{Introduction}

While supply chain models focus on minimizing logistic costs, marketing models focus on maximizing revenues by adjusting products' price and by trying to follow closer demand changes. Obviously, a joint approach allows to determine in a more global way the expected profits of organizations. Consequently, models that incorporate the concepts of inventory theory and optimal price have been developed, where demand depends on the price and other factors (e.g., sales, seasonality, and product life-cycle management) for a planning horizon. For example, Kim and Lee (1998) studied the optimal selling price and inventory levels, with sensitive demand to price sales. Since then, there have been some related models that combine production and prices (Deng \& Yano 2006; Ardjmand et al., 2016), requirements planning and price (Geunes et al., 2006; Chen \& Chen 2015), inventory levels and supplier price (van den Heuvel \& Wagelmans 2006; Taleizadeh \& Noori-daryan 2016). In terms of marketing, certain

* Corresponding author

E-mail: hhlopez@uninorte.edu.co (H. López-Ospina)

(C) 2018 Growing Science Ltd. All rights reserved. doi: $10.5267 /$ j. ijiec.2017.6.003

\begin{abstract}
A B S T R A C T
Decision making in supply chains is influenced by demand variations, and hence sales, non-linear optimization model for a two-echelon supply chain, for a unique product. In addition, the model includes the consumers' maximum willingness to pay, taking socioeconomic differences into account. To do so, the constrained multinomial logit for discrete choices is used to estimate demand levels. Then, a metaheuristic approach based on particle swarm optimization is proposed to determine the optimal product sales price and inventory coordination variables. To validate the proposed model, a supply chain of a technological product was chosen and three scenarios are analyzed: discounts, demand segmentation and demand overestimation. Results are analyzed on the basis of profits, lotsizing and inventory turnover and market share. It can be concluded that the maximum willingness to pay must be taken into consideration, otherwise fictitious profits may mislead decision making, and although the market share would seem to improve, overall profits are not in fact necessarily better.
\end{abstract}


models have introduced specific conditions such as discounts (Berger \& Bechwati 2001), payment due dates (Ghoreishi, et al., 2014), and segmentation of demand (Ghoniem \& Maddah 2015). On the other hand, Shavandi et al. (2012) present a constrained multi-product pricing and inventory model in which perishable products are put into three categories: substitute, complementary and independent; to solve the model genetic algorithm is developed. However, it is important to note that in most of these studies, the demand is modeled with linear and price elasticity functions, which do not necessarily capture all key aspects in the customers purchase behavior. Then, this paper proposes a model that incorporates the changes in demand and its influence on the price adjustment and on the logistic costs associated with inventory levels, in a coordinated problem between a supplier and a vendor. Also, the model considers that there are different socioeconomic groups with different product valuation, hence with different maximum willingness to pay. For the proposed model, the I-JPLMSP model (Yaghin et al., 2014) (Integrated join pricing and lotsizing model with sales promotions) is taken as reference because it integrates the level of inventories with the optimal price in a two echelon supply chain, and also it includes discount and sales policies to meet demand. This logistic model assumes a single vendor and supplier, and a unique non-perishable product without seasonality, with an infinite production rate. However, the I-JPLMSP model is built upon a non-linear function of demand based on a multinomial logit distribution (MNL) (Márquez-Díaz et al., 2011). Thus, demand is only evaluated for a single group of customers with the same rating for the product attributes. The I-JPLMSP model aims is to optimize the multi-echelon profits between the vendor and the supplier.

The main contribution of this paper is to extend the I-JPLMSP model to take into account the following conditions. First, customer segmentation to analyze different socioeconomic groups, with different product valuations, for obtaining a more appropriate demand estimation. Second, price constraints are introduced by using the constrained multinomial logit (CMNL) (Martínez et al., 2009) instead of the unconstrained multinomial logit. The main advantage of using the CMNL over traditional MNL is the possibility to include constraints on the product's attributes through penalty functions (Pérez et al., 2016). In particular, the CMNL allows to include a constraint associated with the maximum willingness to pay by customers that directly affects the estimation of demand and optimal price. Finally, to validate the model, a case study in the Colombian market was used, where socio-economic segmentation is quite present and has an impact on demand and product price estimation.

The rest of the paper is organized as follows. Section 2 explains the CMNL for demand estimation. Then, Section 3 starts by presenting the problem statement, and then the formulation of demand based on the CMNL is explained, followed by the formulation of the logistic multi-echelon model, and last by the Model resolution procedure.

\section{The constrained multinomial logit for demand estimation}

In this research, the discrete choice model known as constrained multinomial logit (CMNL) is used (Martínez et al., 2009) to include constraints on the product selling price, taking into account the consumers' maximum willingness to pay. The CMNL assumes that the perceived utility by an agent, i.e., a consumer, who belongs to the socio-economic group $(h)$ associated with the discrete product $(x)$ denoted by $V_{h x}$ is split into a compensatory part (a in Eq. (1)) and another non-compensatory part (b in Eq. (1)) which indicates the feasibility of that alternative to $h$,

$$
U_{h x}=V_{h x}+\frac{1}{\mu} \operatorname{Ln}\left(\varphi_{h x}\right)+\xi_{h x}
$$

(a)

(b) 
where $\operatorname{Ln}\left(\varphi_{h x}\right)$ is a boundary or penalty function imposed by group $h$ to the attributes of the discrete product $x$. The stated penalty, with a logarithm function, allows constraints to be subtly broken by the decision maker (Martínez et al., 2009). The random component $\xi_{h x}$ represents and reflects the inability of the analyst to model all the attributes and changes in preferences and behaviors of individuals, measurement and modeling errors, lack of accurate information, among others. If such inaccuracies are Gumbel distributed with scale parameter $\mu$, then the probability of a consumer, who belongs to group $(h)$, to purchase product $I$ can be represented as in equation (2).

$$
P_{h x}=\frac{\varphi_{h x} \mathrm{e}^{\mu V_{h x}}}{1+\sum_{j} \varphi_{h j} \mathrm{e}^{\mu V_{h j}}} \cdot \quad \forall h \in H
$$

This probability is known as the constrained multinomial logit model (CMNL) (Martínez et al., 2009). There are some interesting and novel applications that are used on modeling demand in a discrete choices context, in areas such as the mode of transport choice (Castro, et al., 2013), the location of schools and their capacity (Castillo-López \& López-Ospina 2015; Martinez, et al., 2011), the optimal price and packaging (Pérez et al., 2016), the subway route choice (Herrera, 2014), place of residence and housing choice (Martínez \& Donoso 2010; López-Ospina, et al., 2016; López-Ospina, et al., 2017 ), food choice (Ding et al., 2012), parking management (Caicedo, et al., 2016) among others. These applications require constrained variables in different contexts, which imply high non-linearity in demand estimation, which also involves high non-linearity when attributes are decision variables within optimization models, such as the selling price. The following sections describe the detailed logistic problem and the non-linear formulation proposed.

\section{The logistic non-linear optimization problem}

\subsection{Problem statement}

The problem modeled in this article is focused on a two-echelon supply chain with a single vendor and a single supplier, trading a single non-perishable product under the assumption of coordination of cycle times for both supplier and vendor. To formulate the problem the following parameters and variables are taken into account:

\section{Parameters}

$H=$ set of socio - economic groups, $h \in H$

$I_{v}=$ holding inventory cost for the vendor

$K_{v}=$ ordering cost for vendor

$C_{v}=$ purshase costfor the vendor

$I_{p}=$ holding inventory cost for the supplier

$A_{p}=$ ordering cost for the supplier

$C_{p}=$ purshase costfor the supplier

$D_{h}(P)=$ demand of each group $h$ depending on the price $P$ of the product

$Q=$ economic order quantity $(E O Q)$

\section{Variables}

$m=$ number of vendor's orders within one supplier's cycle. Coordination constant

$T_{v}=$ duration of vendor's inventory (annual)

$P=$ product selling price

$T_{p}=$ duration of supplier's inventory (annual) 


\section{Assumptions}

- The maximum willingness to pay, that each group $h$ assigns to the product, is known

- The inventory replenishment time is negligible

- Planning time is infinite

- The supplier delivery rate is infinite

- There is a coordination of inventory cycle times between the vendor and the supplier

\subsection{Formulation of demand based on the CMNL}

From the point of view of microeconomic modeling, discrete choice analysis on a product is based on the principle of utility maximization where the price is directly related to observable characteristics of the product. In addition, it is assumed that each individual makes the decision based on the perceived utility of the product, good or service. Hence, this situation can be modeled by random utility models (RUM) initially developed by Block and Marschak (1960). In 1975, Mc Fadden (1975) makes an econometric extension of this theory by considering that a population of individuals do the same choice on a set of alternatives, i.e., that the population can be split up having as a reference common socioeconomic factors in a group of individuals which conditions their choices. Each group $h$ within the population is called cluster (Martínez et al., 2009). A particular case of these models is the multinomial logit, used by Yaghin et al. (2014) to estimate demand $D$, under the assumption of a single socioeconomic group $(H=1)$, as in equation (3).

$$
D(P)=\alpha \frac{\mathrm{e}^{-b P}}{1+\mathrm{e}^{-b P}}, \quad \alpha, b>0
$$

In Eq. (3) the utility function is given by $V=-b P$, assuming a single product valuation attribute, i.e., the price $P$, and its coefficient of variation $-b$, that shows the variation per price unit changed in the utility function. The utility function is negative because for any consumer, an increase in the product price decreases its perceived utility. In addition, the market size is represented by $\alpha$, which allows to obtain a deterministic demand since the demand for that product, at price $P$, can be obtained by multiplying the number of customers by the purchase probability.

This paper proposes a new model for demand estimation, but using the constrained multinomial logit (CMNL), and introducing the following aspects that make demand estimation more realistic: 1. multiple socio-economic groups with similar characteristics to consumers from the same group in order to analyze and describe logistic and demand impacts. It is important to clarify that an aggregate demand will be obtained, that is, the sum of demands for all clusters. 2 . The utility function $U_{h}$ associated with the product depends on the product selling price $P$ and on a set of characteristics $A_{k}, k=1,2, \ldots, K$ that defines product attractiveness, which are assessed for each sub-group $h$, as suggested in equation (4).

$$
U_{h}=\underbrace{-b_{h} P}_{\text {Price valuation }}+\underbrace{\sum_{k}^{K} \beta_{h k} A_{k}}_{\text {Product attractiveness }}+\underbrace{\varepsilon_{h}}_{\text {Modeling errors }} \forall h \in H
$$

In Eq. (4), $\beta_{h k}$ are the coefficients associated with each characteristic $k$ of the product, within characteristics $A_{k}$ assessed by group $h$. Therefore, if it is assumed that the error is independent and identically distributed (IID) Gumbel with scale parameter $\mu$. Then, if $U_{h}$ is introduced in Eq. (3) replacing $V$, the demand for each group or cluster $h$ for the product is defined as:

$$
D_{h}(P)=\alpha_{h} \frac{\mathrm{e}^{-b_{h} P+\sum_{k}^{K} \beta_{h k} A_{k}}}{1+\mathrm{e}^{-b_{h} P+\sum_{k}^{K} \beta_{h k} A_{k}}}, \quad \forall h \in H
$$


Hence, the aggregate demand can be calculated as:

$$
\operatorname{AggD}=\sum_{h} D_{h}(P)
$$

Based on Eq. (5), the probability of not purchasing for each group $h$ is defined as:

$$
\text { (probability of not purchasing })_{h}=\frac{1}{1+\mathrm{e}^{-b_{h} P+\sum_{k}^{K} \beta_{h k} A_{k}}}, \quad \forall h \in H
$$

A third aspect that is integrated to this model is a penalty associated with the maximum willingness to pay for the product, for each group $h$; making demand estimation more realistic. Thus, demand modeling changes from the classic multinomial logit model to the discrete choice model known as CMNL (Eq. 8).

$$
D_{h}(P)=\alpha_{h} \frac{\varphi_{h}^{U}(P) \varphi^{L}(P) \mathrm{e}^{V_{h}}}{1+\varphi_{h}^{U}(P) \varphi^{L}(P) \mathrm{e}^{V_{h}}} . \quad \forall h \in H
$$

Therefore, the perceived utility presented in Eq. (4) becomes Eq. (9) to introduce the maximum willingness to pay for the product, for each group $h$, denoted as $\frac{1}{\mu} \ln \left(\varphi_{h}^{U}(P)\right)$ and an exogenous lower bound for the product price $\frac{1}{\mu} \ln \left(\varphi_{h}^{L}(P)\right)$. These two constraints are defined by a binomial logit model (Castro et al., 2012) (Eq. (11) and Eq. 12), so that each subgroup $h$ can delimit the product choice based on price. The CMNL allows to smoothly integrate those constrains.

$$
\begin{aligned}
U_{h} & =V_{h}+\frac{1}{\mu} \ln \left(\varphi_{h}^{U}(P)\right)+\frac{1}{\mu} \ln \left(\varphi_{h}^{L}(P)\right)+\varepsilon_{h} \quad \forall h \in H \\
V_{h} & =-b_{h} P+\sum_{k=1}^{K} \beta_{h k} A_{k} \\
\varphi_{h}^{U} & =\frac{1}{1+\operatorname{Exp}\left(w\left(P-a_{h}+\rho\right)\right)} \\
\varphi^{L} & =\frac{1}{1+\operatorname{Exp}(w(\gamma-P+\rho))} .
\end{aligned}
$$

In Eqs. (11-12), $\gamma$ and $a_{h}$ are the lower and upper bounds for the product's price, respectively, $w$ is the scale parameter of the binomial logit, and $\rho$ is a parameter defined by Eq. (13), that includes $\eta$ as the value associated with the population's proportion that overrides the associated constraint. It is important to note that if the parameter $\eta$ is set to 0 or 1 , then the given expression for $\rho$ is undefined, because the binominal logit functions can only predict deterministic choices (probabilities equal to zero or one) when the variables tend to infinity (Martínez et al., 2009).

$$
\rho=\frac{1}{w} \ln \left(\frac{1-\eta}{\eta}\right) .
$$

Once the new demand function is defined with the inclusion of the new conditions, the following section shows how this demand is used in a logistic model.

\subsection{Formulation of the logistic multi-echelon model}

This section provides an optimal policy for a two-echelon supply chain. The main idea is to optimize, simultaneously, the selling price, the size of the purchase order to the supplier and the number of purchase orders per cycle, in order to maximize the profit. The utility function $F$, for this particular case, is described in Eq. (14), where the subscripts $v$ y $p$ define the vendor and the supplier, respectively. 


$$
F=\left(\text { Sales }_{v}-\text { Costs }_{v}\right)+\left(\text { Sales }_{p}-\text { Costs }_{p}\right) .
$$

For this model, it is assumed that the vendor is a retailer that purchases the product and resale it. For this reason its total annual profit function, depending on the estimated aggregated demand, is described as follows:

$$
F_{v}=\sum_{h} D_{h}(P) P-\left\{0,5 I_{v} T_{v} \sum_{h} D_{h}(P)+\frac{K_{v}}{T_{v}}+\sum_{h} D_{h}(P) C_{v}\right\}
$$

For the supplier, it is assumed that it is a wholesaler who purchases a product to market it though its distribution channels and make a profit. Thus, an EOQ (economic order quantity) model is assumed resulting in a profit function similar to the vendor's, but with the following differences: (1) supplier profit is calculated based on the vendor purchase price; (2) a formulation (Eq. (16)) was used to coordinate inventories based on reorder time of the supplier, to avoid inventory shortages in the model

$$
T_{p}=m T_{v}
$$

Then, the joint utility function under the assumption of coordination between the two echelons of the supply chain is described by Eq. (17).

$$
\begin{aligned}
& F\left(P, m, T_{v}, T_{p}\right)=\sum_{h} D_{h}(P)\left(P+C_{v}\right)-\left\{0,5(m-1) T_{v} I_{p} \sum_{h} D_{h}(P)+\frac{K_{p}}{m T_{v}}+\sum_{h} D_{h}(P) C_{p}\right\}- \\
& \left\{0,5 I_{v} T_{v} \sum_{h} D_{h}(P)+\frac{K_{v}}{T_{v}}+\sum_{h} D_{h}(P) C_{v}\right\} .
\end{aligned}
$$

\subsection{Model resolution procedure}

The proposed logistic model implies a high non-linearity in estimating demand, where there is a direct relationship, and non-linear, between the restricted demand and the logistic model choices. Consequently, it is not possible to obtain a solution analytically or using an exact method, and therefore heuristics and meta-heuristics must be used. Given that PSO (particle swarm optimization) has shown the effectiveness in highly non-linear optimization problems (Moghadam \& Seyedhosseini, 2010; Hashemi, et al., 2010; Zahara \& Hu, 2008; Xu et al., 2013; Jafari et al., 2013; Karimi-Nasab, et al., 2015; Bai et al., 2016; Kumar, et al., 2016, Guedria, 2016; among others), in this work a PSO was used to solve the logistic model. The Eq. (19) and Eq. (18) show the velocity and position of each particle $i$ for each dimension $d$ at iteration $t$, where $\omega$ is the particle inertia, $C_{1}$ and $C_{2}$ are acceleration constants, best $_{i d}$ is the best position the particle has reached to the current iteration, and best ${ }_{g d}$ is the position of the best particle of the whole swarm, considering a fully connected swarm (Kennedy \& Mendes 2002). Fig. 1 shows the resolution procedure pseudo-code.

$$
\begin{aligned}
& \operatorname{Vel}_{i d}(t)=\omega * \operatorname{Vel}_{i d}(t-1)+C_{1} * r n d *\left(\operatorname{Best}_{i d}-\operatorname{pos}_{i d}(t-1)\right)+ \\
& C_{2} * r n d *\left(\operatorname{Best}_{g d}-\operatorname{pos}_{i d}(t-1)\right), \\
& \operatorname{pos}_{i d}(t)=\operatorname{pos}_{i d}(t-1)+\operatorname{Vel}_{i d}(t) .
\end{aligned}
$$

The particle coding scheme has three dimensions based on three decision variables: the selling price of the product $(P)$, the number of shipments within the single supplier cycle $(m)$, and finally, the duration of the inventory for the vendor $\left(T_{v}\right)$. The fourth decision variable $\left(T_{v}\right)$ is not integrated into the coding scheme because of its dependent relationship to $\left(T_{v}\right)$, according to equation (16). 


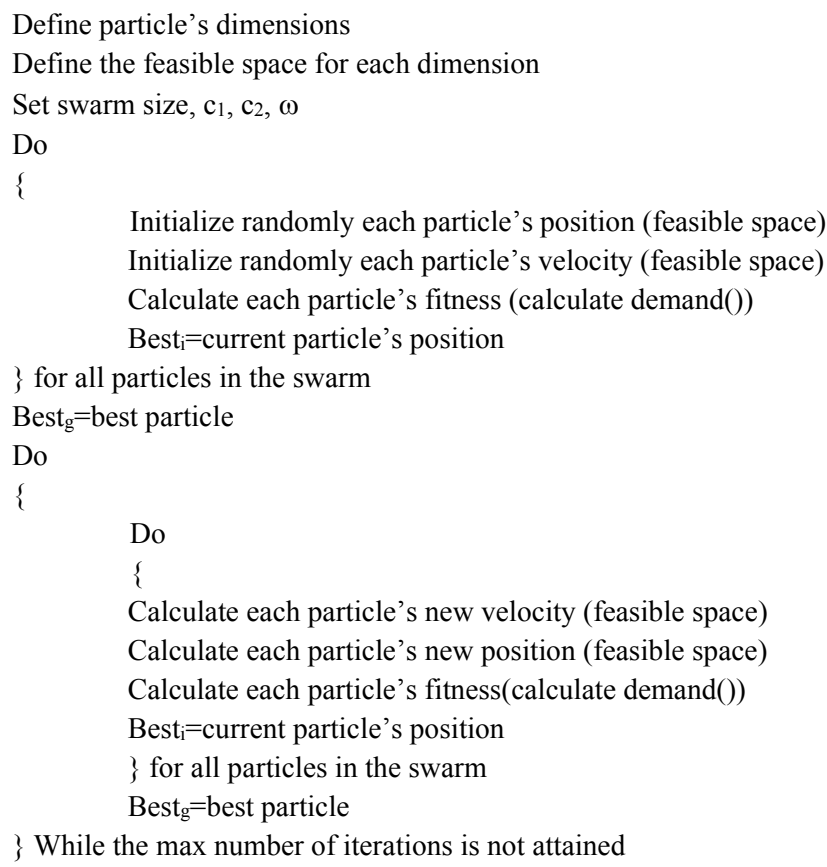

\} While the max number of iterations is not attained

Fig 1. Resolution procedure based on PSO

Eq. (17) is used as the PSO objective function, and for each variable the following feasibility constraints are true as it is explained below.

\section{Feasibility constraint for $m$}

To analyze this constraint, it is assumed that variable $m$ is continuous, thus the first derivate of Eq. (17) regarding $m$ is defined as:

$$
\begin{aligned}
\frac{\partial F}{\partial m}=\sum_{h} D_{h}(P) & \left(P+C_{v}\right)-\left\{0,5(m-1) T_{v} I_{p} \sum_{h} D_{h}(P)+\frac{K_{p}}{m T_{v}}+\sum_{h} D_{h}(P) C_{p}\right\} \\
& -\left\{0,5 I_{v} T_{v} \sum_{h} D_{h}(P)+\frac{K_{v}}{T_{v}}+\sum_{h} D_{h}(P) C_{v}\right\},
\end{aligned}
$$

then:

$$
\frac{\partial F}{\partial m}=\left[\frac{K_{p}}{m^{2} T_{v}}-K_{v}\right]-0,5 T_{v} I_{p} \sum_{h} D_{h}(P) .
$$

Therefore, a critical point of the function is found, obtaining:

$$
m=\frac{\sqrt{2} \sqrt{K_{p}}}{\sqrt{T_{v}\left[T_{v} I_{p} \sum_{h} D_{h}(P)+2 K_{v}\right]}} .
$$

Analyzing the second derivative regarding $m$ :

$$
\frac{\partial^{2} F}{\partial m^{2}}=-\frac{2 K_{p}}{m^{3} T_{v}} .
$$

Since the second derivative is negative, then the critical point is a relative maximum. Through Eq. (22), it can be stated that $m$ is a non-decreasing function of $P$. Thus, the maximum number of shipments can be set as 
- $m_{\max } \rightarrow T_{v \min } \neq 0 \rightarrow 0,1$

- $P \rightarrow P_{\max }$, i.e $\sum_{h} D_{h}(P) \rightarrow 0$

$$
\left.m_{\max }=\sqrt{\frac{K_{p}}{0,1 * A_{v}}}\right\rceil .
$$

Thus it can be concluded that the maximum value of the profit function is associated with an integer value $m$ in the interval $m=\left[1, m_{\max }\right]$.

Feasibility constraint for $T_{v}$

$T_{v}$ assumes a lower and an upper level of duration, which depends on market dynamics and product obsolescence. As a result, $T_{v}$ strongly depends on the chosen market and product that are evaluated on the proposed model, considering that $T_{v} \neq 0$.

\section{Feasibility constraint for $P$}

Within the logistic model a purchase price $C_{v}$ was established for the vendor, which is defined as the lower bound of the price $P$, and the upper bound of the price is given by the maximum willingness to pay among all socio-economic groups $h$. Taken into account that the CMNL allows the price not to strictly respect these constraints, by a soft penalty (as shown in Fig. 2), hard upper and lower bounds were established for the PSO, up to half of the purchase price $C_{v}$ (lower bound, $C_{v} / 2$ ) and to double of the maximum willingness to pay among all socio-economic groups (upper bound, $2 * \max \left\{a_{h}\right\}$ ).

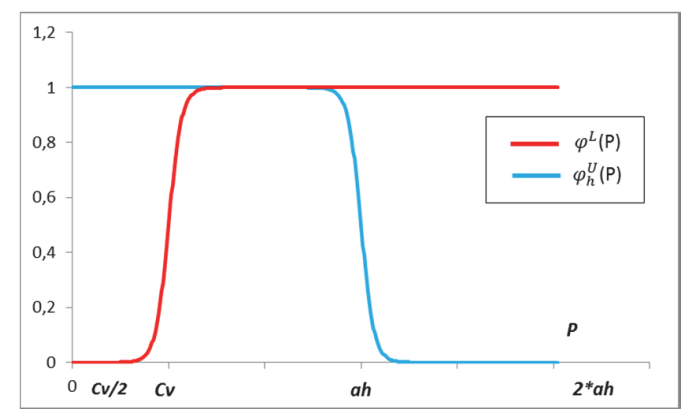

Fig 2. Penalty functions of constrained Logit

\section{Implementation and results}

To validate the proposed model the digital television market was chosen, particularly in the Colombian context, based on the previous study of González and Serna (2013). From this work, the 32-inch LED television was taken as the reference because of its variance in demand. Only in 2013, 1'700.000 screens were sold in the country, and in 2014 the sales of these products were around 2 million units. As far as the sizes, 32-inch models are consolidated as the preferred size by Colombians with more than $52 \%$ of sales, and LED technology accounts for $90 \%$ of sales (Tiempo, 2016a; Tiempo, 2016b). In the following sections, the socio-economic groups, costs, and logit parameters are defined, and the implementation procedure and results analysis are reported.

\subsection{Socio-economic groups and attributes definition}

In order to obtain the characteristics of people that directly affect the maximum willingness to pay, a survey with the following study variables was designed: age, gender, zone, neighborhood and price. The zone and neighborhood variables are allowed to define three socio-economic groups, i.e., lower, middle, upper social classes or stratification; according to the demographic characterization of Bogotá ( 2003). 
From the obtained results, an analysis of variance was performed from which it was concluded, with a significance level of $5 \%$, that the single studied variable that affects the maximum willingness to pay is the socio-economic group to which the individual belongs. Additionally, to define the upper and lower bound constraints, the maximum willingness to pay for each socio-economic group and the market size (193436 inhabitants) based on the target population defined by surveys were obtained. Such values are presented in Table 1.

Table 1

Socio-economic groups

\begin{tabular}{lll}
\hline \multicolumn{1}{c}{ Socio-economic groups } & Maximum willingness to pay (COP\$) & Market size (inhabitants) \\
& 1 dollar is equivalent to 3000 COP\$ & \\
\hline Lower & 894.615 & 50294 \\
Middle & 1.190 .604 & 115288 \\
Upper & 1.958 .333 & 27855 \\
\hline
\end{tabular}

From these results, the price sensitivity coefficient is also defined as shown in Table 2.

Table 2

Price sensitivity coefficient

\begin{tabular}{ll}
\hline Socio-economic groups & Price sensitivity coefficient \\
\hline Lower & 0.725 \\
Middle & 0.5375 \\
Upper & 0.225 \\
\hline
\end{tabular}

Finally, through direct observation of the market, the minimum selling price of 32-inches LED televisions is set to COP\$ 620.999 .

\subsection{Costs definition}

Because the costs associated in Eq. (17) are strategic values of enterprises and therefore is not readily available information, additional parameters were included so such values could be estimated. Then, the parameter $P V$ was included and it refers to the average current selling price in the market, COP\$ 927.104. As well, the parameter $P G$ was included to represent the expected profit percentage. Three reference values of $30 \%, 40$ and $50 \%$ were fixed for $P G$. The parameter $P V$ is equal to both supplier and vendor, as the logistic model aims to balance the perceived profits for the two echelons in the chain. Consequently, to set the values of $C_{v}$ and $C_{p}$ the relationship between the vendor and supplier was defined as shown in Fig. 3.

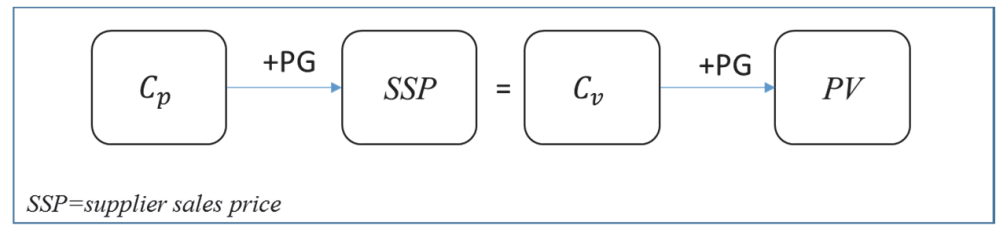

Fig 3. Relationship between vendor and supplier costs

Similarly, the costs of holding inventory and ordering were defined under the established relationships in Table 3.

Table 3

Holding inventory costs and ordering costs for vendor and supplier

\begin{tabular}{lll}
\hline & Cost & Relation \\
\hline Vendor & Holding & 0,15 times \\
& Ordering & 41,67 times \\
\hline Supplier & Holding & 0,08 times \\
& Ordering & 125 times \\
\hline
\end{tabular}




\subsection{Parameters for the $C M N L$}

As proposed by Castro et al. (2013), the penalty is defined as the product of both, the upper and lower constraints. Taking into account that both constraints and their thresholds are independent, the results of constraints by varying the parameters $(\boldsymbol{w})$ and $(\eta)$ in Eqs. (11-13) were analyzed. Then, it was evident that the penalties were too strict when $\eta$ took values lower than 0.9 , and after this value, variations were not significant. In addition, it was noted that the more $\boldsymbol{w}$ increased, there were not large variations. For this reason, it was established that an intermediate penalty would be used, for which $\boldsymbol{w}=\mathbf{0 . 5}$ was fixed.

\subsection{Procedure implementation}

The implementation of the proposed model was run on R Statistics software. To implement the solution, and based on some control instances, the parameters in Table 4 were used, which allowed convergence of the model.

\section{Table 4}

Values for PSO parameters

\begin{tabular}{ll}
\hline Parameters & Values \\
\hline Par (Components of each individual) & Empty array of length 3 \\
Fn (Adaptability function) & Joint gains function equation (17) \\
Lower (Lower constraints) & Array containing lower bounds for each variable \\
Upper(Upper constraints) & Array containing upper bounds for each variable \\
Maxit (Number of iterations) & 1500 \\
$S$ (Population size) & 60 \\
$W$ (Decreasing inertia) & Minimum value: 0,02 \\
& Maximum value: 2 \\
\hline
\end{tabular}

\subsection{Results analysis}

Given the general description of the optimization problem, the proposed model was evaluated against three scenarios. The first scenario analyzes the impact of discounts by means of sensitivity analysis. The second scenario compares the model without including the price constraints in the logit demand function. More, to obtain an approach that depicts the influence of customer behavior in demand estimation, a third scenario including socio-economic segmented demand was assessed. In order to assess the model accuracy and its behavior in the proposed scenarios, the base model was considered regardless of the product attractiveness, i.e., assessment of the attributes other than price in the utility function. Hence, the analysis of the base model and product attractiveness are presented at first, followed by the scenarios.

\section{Analysis of the base model}

Results obtained from the base model are reported in Table 5. When performing a comparative analysis among the three expected profit percentages, it can be noted that the biggest profit obtained was when $P G=50 \%$. Profit is 1.39 and 1.15 times above profits obtained with $P G=30 \%$ and $P G=40 \%$, respectively. This behavior occurs because when the expected profit for the company increases, the objective function is affected in the same way due to their direct relationship. Regarding the demand, it is evident that the lower the selling price, the more increase in demand by the following relation: for every two percentage points that the price decreases, demand increases about $2.7 \%$. As for the inventory level, it can be observed that for an expected profit of $50 \%, 7$ orders per year are made to meet its annual demand. These orders will be made every 53 days using an economic order quantity of 6243 units. In contrast, the cycle time for the supplier inventory will be 106 days within which the vendor will make 2 orders. For the expected profits of $30 \%$ and $40 \%$, it is perceived to have the same number of orders per year compared to the value of $50 \%$. However, it is possible to observe that the total costs increase as the expected profit percentage decreases. Therefore, the model with expected profit of $50 \%$ has the lowest total costs, being $47.4 \%$ and $19.6 \%$ lower than those models with expected profits set to $30 \%$ and $40 \%$, respectively. This 
phenomenon is associated to holding inventory costs, since the more the duration of inventory increases for the vendor and supplier, the lower the expected profit percentage. Finally, when comparing the average price obtained by direct observation of the market $(\$ 927,104)$ to the three studied values, the model that gets closest to this number is the model with $P G=50 \%$. For this reason, an expected profit of $50 \%$ was used for the following analysis.

Table 5

Results of base model

\begin{tabular}{llll}
\hline Parameters & $P G=30 \%$ & $P G=40 \%$ & $P G=50 \%$ \\
\hline Objective Function (COP\$) & $24,171,500,000$ & $29,250,350,000$ & $33,720,110,000$ \\
Price (COP \$) & $1,079,779$ & $1,050,611$ & $1,030,514$ \\
Number of shipments within one supplier's cycle & 2 & 2 & 2 \\
Duration of vendor's inventory (days) & 55 & 54 & 53 \\
Number of shipments per year & 7 & 7 & 7 \\
Duration of supplier's inventory (days) & 110 & 107 & 106 \\
$Q$ & 6023 & 6159 & 6243 \\
Demand & 40081 & 41903 & 43050 \\
Total costs for vendor (COP \$) & $6,484,300,000$ & $23,723,450,000$ & $20,305,930,000$ \\
Total costs for supplier (COP \$) & $18,634,300,000$ & $14,359,020,000$ & $10,293,500,000$ \\
\hline
\end{tabular}

To observe the behavior of PSO throughout iterations, the convergence curve for the objective function for the case of an expected profit set to 50\% is shown in Fig. 4.

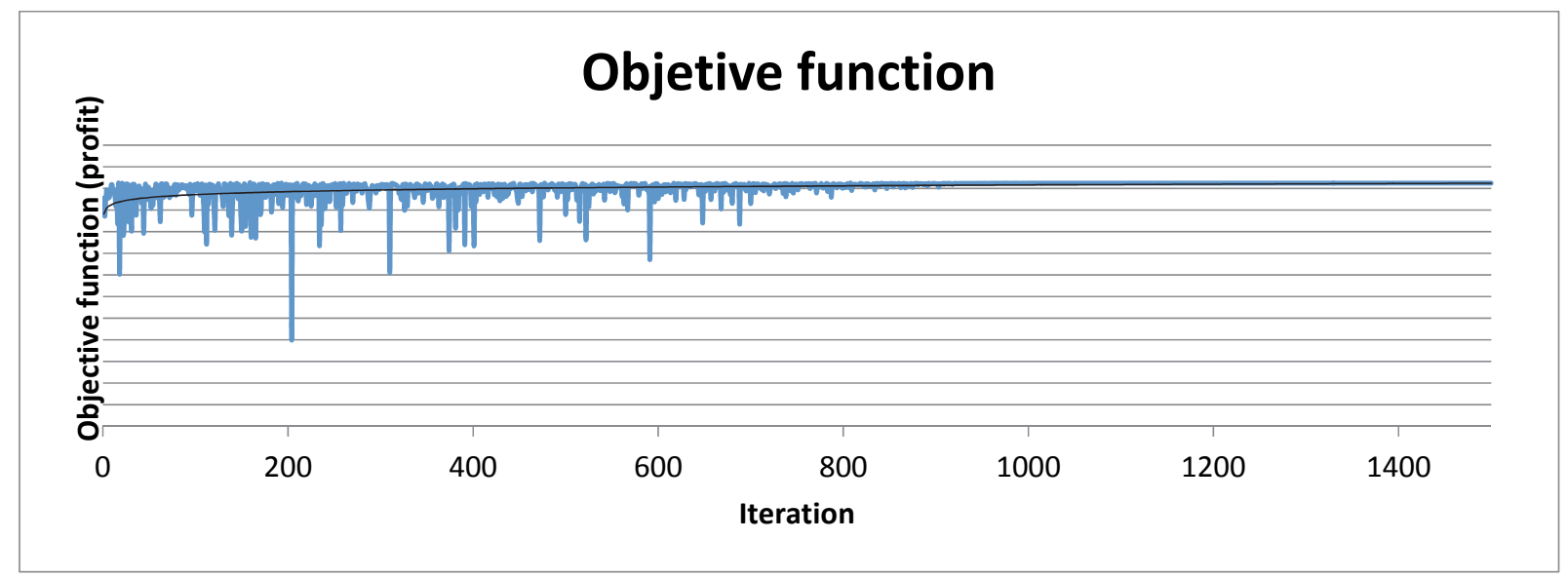

Fig 4. Convergence chart for base model

\section{Analysis of product attractiveness}

To analyze product attractiveness, a sensibility analysis study on two factors was conducted: socioeconomic group and attractiveness, each of them with three levels (lower, middle, upper), being the price the response variable.

Table 6

Sensibility analysis

\begin{tabular}{llllll}
\hline $\begin{array}{l}\text { Analysis of variance } \\
\text { Origin of variations }\end{array}$ & Sums of squares (COP\$) & Degrees of freedom & Average of squares & F & P-value \\
\hline Social stratum $(E)$ & $6,484,778,577,204$ & 2 & $8.24 \mathrm{E}+12$ & $1.49 \mathrm{E}+06$ & $0.00 \%$ \\
Attraction $(A)$ & $9,750,856,924$ & 2 & $4.88 \mathrm{E}+09$ & $8.83 \mathrm{E}+02$ & $0.00 \%$ \\
E\&A & $2,409,729,336$ & 4 & $6.02 \mathrm{E}+08$ & $1.09 \mathrm{E}+02$ & $0.00 \%$ \\
Error & $1,590,787,406$ & 288 & $5.52 \mathrm{E}+06$ & & \\
\hline Total & $16,498,529,950,870$ & 296 & $5.57 \mathrm{E}+10$ & \\
\multicolumn{2}{c}{$\alpha=5 \%$} & & \\
\hline
\end{tabular}


All possible values of attractiveness were evaluated within the intervals defined above and 33 results were obtained for each possible combination between the levels of social stratification and product attractiveness. Once these data obtained, an analysis of variance was performed as shown in Table 6 . With a significance level of $5 \%$ it was evident that social stratification, product attractiveness and the combination of both factors significantly affect the optimal price, and therefore, they also affect significantly the entire logistic model. Based on the adjusted coefficient of determination, it was found that $99.9 \%$ of the observed price variation is explained by the model. Given the above results, it can be noted that product attractiveness becomes relevant in this model for both price definition and inventory management. Nevertheless, it was stated that attractiveness would be equal to 0 in the following analysis, i.e., the utility function depends only on the price variable, similar to the model developed on the model I-JPLMSP designed and analyzed by Yaghin et al. (2014).

\subsubsection{Scenario 1: Discounts analysis}

In order to analyze the logistic impact by incorporating the sales discounts (r), $r$ is defined based on the expected profit percentage (PG). To avoid losses, the following relationships were established among the selling price found in the market (including discounts) and the purchase cost of vendor:

$$
\begin{aligned}
& C_{v} \leq P V *(1-r) \\
& C_{v} \leq \frac{C_{v}}{(1-P G)}(1-r)
\end{aligned}
$$

Thus:

$$
r \leq P G
$$

Then, the utility function of CMNL model was adjusted as shown in equations (28)-(30)

$$
\begin{aligned}
& U_{h}=-b_{h} P(1-r) \quad \forall h \in N \\
& D_{h}(P)=\alpha_{h} \frac{\mathrm{e}^{-b_{h} P(1-r)}}{1+\mathrm{e}^{-b_{h} P(1-r)}} \quad \forall h \in N \\
& F\left(P, m, T_{v}, T_{p,}\right)=\sum_{h} D_{h}(P)\left(P(1-r)+C_{v}\right)-\left\{0,5(m-1) T_{v} I_{p} \sum_{h} D_{h}(P)+\frac{A_{p}}{m T_{v}}+\sum_{h} D_{h}(P) C_{p}\right\} \\
& -\left\{0,5 I_{v} T_{v} \sum_{h} D_{h}(P)+\frac{A_{v}}{T_{v}}+\sum_{h} D_{h}(P) C_{v}\right\}
\end{aligned}
$$

Finally, based on an expected profit of 50\% (upper bound) and on direct market observation, it was established that the most common discount on the selling price is $20 \%$, as reported in Table 7 . From these results it is noted that by incorporating the discount, all the associated parameters are affected, especially the demand and profits. With a $20 \%$ discount, demand increased $4.29 \%$ with respect to base model, but the total profit decreased by $36.6 \%$.

\section{Table 7}

Results for $20 \%$ discount

\begin{tabular}{ll}
\hline Parameters & $\mathrm{PG}=50 \%$ \\
\hline Objective Function (COP\$) & $24,690,610,000$ \\
Price(COP\$) & $1,030,514$ \\
Number of shipments within one supplier's cycle $(\mathrm{m})$ & 2 \\
Duration of vendor's inventory (days) & 53 \\
Number of shipments per year & 7 \\
Duration of supplier's inventory (days) & 106 \\
$Q$ & 6510 \\
Demand & 44896 \\
Total costs for vendor (COP\$) & $20,305,930,000$ \\
Total costs for supplier (COP\$) & $10,293,500,000$ \\
Price with 20\% discount (COP\$) & 824,411 \\
\hline
\end{tabular}




\subsubsection{Scenario 2: Logit model}

The objective of this scenario was to analyze the impact of constraints and hence, these were omitted in the calculation of demand with the classical MNL. The results of this scenario are shown in Table 8 . From those, it can be observed that by not considering the constraints in the model, demand was overestimated at $26.8 \%$ compared to the base model. In turn, this overestimation means that profit increases 4 times above the base model. Additionally, it is evident that price tended to the upper bound imposed, so that for a product such as 32-inch LED television, a high price that is 4,2 times the one found in the market was held.

\section{Table 8}

Results of Logit model

\begin{tabular}{ll}
\hline Parameters & $\mathbf{P G}=\mathbf{5 0 \%}$ \\
\hline Objective Function (COP\$) & $200,486,000,000$ \\
\hline Price (COP\$) & $\$ 3,916,667$ \\
Number of shipments within one supplier's cycle $(m)$ & 2 \\
Duration of vendor's inventory (days) & 47 \\
Number of shipments per year & 8 \\
Duration of supplier's inventory (days) & 94 \\
$Q$ & 7031 \\
Demand & 54611 \\
Total costs for vendor (COP\$) & $25,709,260,000$ \\
Total costs for supplier (COP\$) & $3,012,920,000$ \\
\hline
\end{tabular}

\subsubsection{Scenario 3: Segmented demand}

In order to analyze the influence and logistic impacts of each socio-economic group defined within the demand, a model was run for each group, taking into account a product attractiveness equal to 0 , an expected profit equal to $50 \%$ and an estimated demand through the CMNL. The results obtained are presented in Table 9. Meanwhile, Table 10 shows the contribution of each socio-economic group to the aggregate demand of the base model. From these results it can be noted that, as for the base model, the greatest demand is associated to middle-stratum, followed by the lower-stratum and finally by the upperstratum. This demand behavior is explained due to the distribution of the surveyed population, since $26 \%$ corresponds to lower-social stratum, 59.6\% to middle-stratum, and 14.4\% to upper-stratum. Furthermore, it is noted that demand for each group varies in different proportions in relation to the selling price, and therefore, by taking the price of the base model as a reference, it was evident that price decreased by $7 \%$ in lower-stratum, and demand increased by $12 \%$. For middle-social stratum, price increased $1 \%$ and consequently demand decreased $1.4 \%$. For the latter group, the upper-social stratum, the price increased by $26 \%$ and demand decreased by $7 \%$.

\section{Table 9}

Results for aggregate demand

\begin{tabular}{|c|c|c|c|}
\hline Parameters & Lower & Middle & Upper \\
\hline Objective Function (COP\$) & $\$ 912,741,000$ & $\$ 22,901,800,000$ & $\$ 1,457,199,000$ \\
\hline Price $(C O P \$)$ & $\$ \quad 962,381$ & $\$ \quad 1,042,319$ & $1,386,959$ \\
\hline Number of shipments within one supplier's cycle & 2 & 2 & 2 \\
\hline Duration of vendor's inventory (days) & 93 & 65 & 297 \\
\hline Number of shipments per year & 4 & 6 & 1.2 \\
\hline Duration of supplier's inventory (days) & 185 & 129 & 595 \\
\hline$Q$ & 3571 & 5117 & 823 \\
\hline Demand & 14089 & 28928 & 1010 \\
\hline Total costs for vendor (COP\$) & $\$, 731,220,000$ & $\$ 13,696,550,000$ & $\$ \quad 694,587,900$ \\
\hline Total costs for supplier (COP\$) & $\$, 446,009,000$ & $\$ \quad 6,963,481,000$ & $372,309,900$ \\
\hline
\end{tabular}


Regarding the duration of supplier's inventory, it can be observed that an order is made every 297 days for the upper-social stratum in order to meet their demand, being its inventory cycle of 595 days. This long duration may significantly affect the devaluation of inventory, meaning that as time passes the monetary unit will lose their commercial value because of technology advances, which significantly impact the televisions market, with high risk of technology obsolescence.

Finally it is noted that the target population is located at middle-social stratum since this stratum contributes $65.7 \%$ of total demand. For this reason, and to facilitate comparison among different the proposed scenarios, the impact of this scenario was assessed only by using the middle-stratum.

Table 10

Influence of groups on aggregate demand

\begin{tabular}{llll}
\hline Sub-groups & Lower & Middle & Upper \\
\hline$P G=50 \%$ & 12623 & 29341 & 1086 \\
\hline
\end{tabular}

\section{Conclusions}

This paper has presented a logistic optimization, non-linear, multi-echelon model that integrates the selling price of a product and the level of inventories, including a constraint about the maximum willingness to pay of customers, taking into account different socio-economic groups. To estimate the demand, the discrete choice multinomial restricted logit (CMNL) model was used in order to include soft constraints on the purchase price. Moreover, the optimal purchase price, as well as the coordination inventory variables, were obtained through a metaheuristic based on particle swarm optimization (PSO).

To validate the proposed model, the population was segmented into lower, middle and upper classes depending on their income, according to the Colombian social stratification. In assessing the behavior of each socio-economic group faced to the choice of the same product, the choice is conditioned by the maximum willingness to pay. In contrast, from the vendor's perspective it is important to consider the minimum selling price. Therefore, there is a need to use the constrained multinomial logit model for modeling demand, in order to include the aforementioned constraints.

Through the application example, the behavior of the proposed aggregate demand model could be analyzed against three scenarios. The first scenario focused on the base model with a sensitivity analysis on possible discounts, the second scenario estimated demand by means of a non-constrained multinomial logit model and the third scenario contemplated a segmented demand for each socio-economic group. From the first scenario, it was observed that when considering a discounts policy based on the vendor's expected profit, discounts increased market share but not necessarily generated higher profits compared to those obtained with the base model. That is, the value of the objective function decreased, compared to the base model, and in turn, demand showed an increase which can be taken as a growth strategy to increase market share in the long term.

For the second scenario, the non-constrained logit model obtained different results compared to other proposed scenarios. By omitting constraints, a significant increase in demand and in joint profits of supplier and vendor were observed. However, by not including constraints, this model is unreliable because it is not adapted to realistic consumer behavior. Consequently, the inventory level is affected by an increase of $12.6 \%$, which can be risky due to an overestimation of demand that brings as a result a lower product turnover. In addition, it is evident that the selling price of the product obtained in this scenario differs to the maximum willingness to pay of the target population, reinforcing the low turnover of the product compared with the scenario that contemplates constraints. On the other hand, the third scenario, with segmented demand, allows to identify different target populations, letting companies to create strategies for each niche market, focused on the needs of this population and in order to develop customized products or services. Furthermore, a sales policy could be defined based on the location of a 
vendor and on the socio-economic environment where it is found, aimed to establish different prices that are aligned with the highest willingness to pay of the socio-economic group. Finally, future work may be focused on expanding the model to integrate multiple products, multiple vendors and/or suppliers, and to include independent prices for each vendor.

\section{References}

Ardjmand, E., Weckman, G. R., Young, W. A., Sanei Bajgiran, O., \& Aminipour, B. (2016). A robust optimisation model for production planning and pricing under demand uncertainty. International Journal of Production Research, 54(13), 3885-3905.

Bai, T., Kan, Y. B., Chang, J. X., Huang, Q., \& Chang, F. J. (2017). Fusing feasible search space into PSO for multi-objective cascade reservoir optimization. Applied Soft Computing, 51, 328-340.

Berger, P. D., \& Bechwati, N. N. (2001). The allocation of promotion budget to maximize customer equity. Omega, 29(1), 49-61.

Block, H. D., \& Marschak, J. (1960). Random orderings and stochastic theories of responses. Contributions to probability and statistics, 2, 97-132.

Bogotá, A. M. (2003). CARACTERIZACIÓN SOCIOECONÓMICA DE BOGOTÁ Y LA REGIÓNV8.

Caicedo, F., Lopez-Ospina, H., \& Pablo-Malagrida, R. (2016). Environmental repercussions of parking demand management strategies using a constrained logit model. Transportation Research Part D: Transport and Environment, 48, 125-140.

Castillo-López, I., \& López-Ospina, H. A. (2015). School location and capacity modification considering the existence of externalities in students school choice. Computers \& Industrial Engineering, 80, 284294.

Castro, M., Martínez, F., \& Munizaga, M. A. (2013). Estimation of a constrained multinomial logit model. Transportation, 40(3), 563-581.

Chen, M., \& Chen, Z. L. (2015). Recent developments in dynamic pricing research: multiple products, competition, and limited demand information. Production and Operations Management, 24(5), 704731.

Deng, S., \& Yano, C. A. (2006). Joint production and pricing decisions with setup costs and capacity constraints. Management Science, 52(5), 741-756.

Ding, Y., Veeman, M. M., \& Adamowicz, W. L. (2012). The influence of attribute cutoffs on consumers' choices of a functional food. European Review of Agricultural Economics, 39(5), 745-769.

Geunes, J., Romeijn, H. E., \& Taaffe, K. (2006). Requirements planning with pricing and order selection flexibility. Operations Research, 54(2), 394-401.

Ghoniem, A., \& Maddah, B. (2015). Integrated retail decisions with multiple selling periods and customer segments: optimization and insights. Omega, 55, 38-52.

Ghoreishi, M., Weber, G. W., \& Mirzazadeh, A. (2015). An inventory model for non-instantaneous deteriorating items with partial backlogging, permissible delay in payments, inflation-and selling price-dependent demand and customer returns. Annals of Operations Research, 226(1), 221-238.

González, C., \& Serna, N. (2013). The consumer's choice among television displays: A multinomial logit approach. Lecturas de Economía, (79), 199-228.

Guedria, N. B. (2016). Improved accelerated PSO algorithm for mechanical engineering optimization problems. Applied Soft Computing, 40, 455-467.

Hashemi, S. M., Rezapour, M., \& Moradi, A. (2010). An effective hybrid PSO-based algorithm for planning UMTS terrestrial access networks. Engineering Optimization, 42(3), 241-251.

Herrera Rojas, C. (2014). Desarrollo de un modelo de elección de ruta en metro. Master thesis. Universidad de Chile.

Van den Heuvel, W., \& Wagelmans, A. P. (2006). A polynomial time algorithm for a deterministic joint pricing and inventory model. European Journal of Operational Research, 170(2), 463-480.

Jafari, H., Soltani, A., \& Soltani, M. (2013). Measuring the performance of FCM versus PSO for fuzzy clustering problems. International Journal of Industrial Engineering Computations, 4(3), 387-392. 
Karimi-Nasab, M., Modarres, M., \& Seyedhoseini, S. M. (2015). A self-adaptive PSO for joint lot sizing and job shop scheduling with compressible process times. Applied Soft Computing, 27, 137-147.

Kennedy, J., \& Mendes, R. (2002). Population structure and particle swarm performance. In Evolutionary Computation, 2002. CEC'02. Proceedings of the 2002 Congress on (Vol. 2, pp. 1671-1676). IEEE.

Kim, D., \& Lee, W. J. (1998). Optimal joint pricing and lot sizing with fixed and variable capacity. European Journal of Operational Research, 109(1), 212-227.

Kumar, E. V., Raaja, G. S., \& Jerome, J. (2016). Adaptive PSO for optimal LQR tracking control of 2 DoF laboratory helicopter. Applied Soft Computing, 41, 77-90.

López-Ospina, H. A., Martínez, F. J., \& Cortés, C. E. (2016). Microeconomic model of residential location incorporating life cycle and social expectations. Computers, Environment and Urban Systems, 55, 33-43.

López-Ospina, H. A., Cortés, C. E., \& Martínez, F. J. (2017). Residential relocation dynamics: A microeconomic model based on agents' socioeconomic change and learning. The Journal of Mathematical Sociology, 41(1), 46-61.

Márquez-Díaz, L. G., Gallo-González, L. A., \& Chacón-Pérez, C. A. (2011). Influence of Parking Costs on the Use of Cars in Bogota. Ingeniería y Universidad, 15(1), 105-124.

Martínez, F., Aguila, F., \& Hurtubia, R. (2009). The constrained multinomial logit: A semi-compensatory choice model. Transportation Research Part B: Methodological, 43(3), 365-377.

Martínez, F., \& Donoso, P. (2010). The MUSSA II land use auction equilibrium model. In Residential Location Choice (pp. 99-113). Springer Berlin Heidelberg.

Martinez, F. J., Tamblay, L., \& Weintraub, A. (2011). School locations and vacancies: a constrained logit equilibrium model. Environment and Planning A, 43(8), 1853-1874.

Moghadam, B., \& Seyedhosseini, S. (2010). A particle swarm approach to solve vehicle routing problem with uncertain demand: A drug distribution case study. International Journal of Industrial Engineering Computations, 1(1), 55-64.

McFadden, D. (1975). The revealed preferences of a government bureaucracy: Theory. The Bell Journal of Economics, 401-416.

Perez, J., Lopez-Ospina, H., Cataldo, A., \& Ferrer, J. C. (2016). Pricing and composition of bundles with constrained multinomial logit. International Journal of Production Research, 54(13), 3994-4007.

Shavandi, H., Mahlooji, H., \& Nosratian, N. E. (2012). A constrained multi-product pricing and inventory control problem. Applied Soft Computing, 12(8), 2454-2461.

Taleizadeh, A. A., \& Noori-daryan, M. (2016). Pricing, manufacturing and inventory policies for raw material in a three-level supply chain. International Journal of Systems Science, 47(4), 919-931.

Tiempo, Casa Editorial El. (2016a). "El Mercado de Televisores Mueve US\$ 1.000 Millones Al Año." Portafolio.co. Accessed May 27.

Tiempo, Casa Editorial. (2016b). "Mundial de Brasil Cambiará El Ciclo de Ventas de Televisores." Portafolio.co. Accessed May 27.

Xu, J., Zeng, Z., Han, B., \& Lei, X. (2013). A dynamic programming-based particle swarm optimization algorithm for an inventory management problem under uncertainty. Engineering Optimization, 45(7), 851-880.

Yaghin, R., Ghomi, S. M. T., \& Torabi, S. A. (2014). Enhanced joint pricing and lotsizing problem in a two-echelon supply chain with logit demand function. International Journal of Production Research, 52(17), 4967-4983.

Zahara, E., \& Hu, C. H. (2008). Solving constrained optimization problems with hybrid particle swarm optimization. Engineering Optimization, 40(11), 1031-1049.

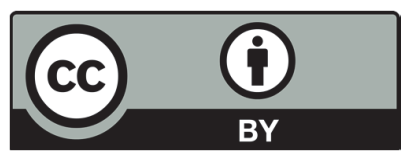

(C) 2018 by the authors; licensee Growing Science, Canada. This is an open access article distributed under the terms and conditions of the Creative Commons Attribution (CCBY) license (http://creativecommons.org/licenses/by/4.0/). 